\title{
NEUROGENESIS AND THE IMPACT OF STEROID HORMONES ON BEHAVIOUR
}

\section{NEUROGENEZA I UTICAJ STEROIDNIH HORMONA NA PONASANJE}

\author{
Bojana Rankov Petrović', Aleksandra Rašić Marković', Dragan Hrnčić', Olivera Stanojlović́
}

\section{Summary}

It took almost a century to get over the dogma of impossibility of adult neurogenesis. A growing number of researches in the past few decades have brought phenomena of adult neurogenesis into light. Ideas of therapeutic possibilities of neural stem cells in managing brain stroke, traumatic brain and spinal cord injury, as well as growing number of neurodegenerative diseases, represent the basis of huge research projects.

After the development of CNS is finished, neurogenesis continues in two regions of the adult brain: sub ventricular zone of lateral ventricles and sub granular zone of dentate gyri of hippocampus. The process of neurogenesis brings two main questions concerning the regulatory mechanism: which factors enhance or suppress it and what is the significance of the process in humans. Brain development is under crucial influence of steroid hormones (effects are mediated through gene interaction or by neuromodulation of ion channel), so their influence on behaviour cannot be neglected. Studies have shown that hormones modulate learning and memory, but the specific roles of each of them should be monitored under a wide context of time, pre-exposition test manipulation, training as well as type of testing. Stress is another important factor in the regulation of adult neurogenesis, but current results highlight the importance of the opposite direction as well and young neurons interaction activity with HPA axis.

Neurosteroids (allopregnanolone, dihydroepiandrosterone) are synthetized in the brain, and their concentrations are found higher than in blood of mammals. A number of steroidogenic enzymes (rate limiting enzymes in synthesis from cholesterol) are targeted in the brain, spinal cord and peripheral nervous system. The significance of neurosteroids' existence in brain tissue is explored through experiments of epileptogenesis.

Numerous researches are trying to determine whether and how hormone alterations in neuroplasticity and neurogenesis are related to changes in cognition. Progesterone has been shown to improve neurologic outcome in multiple experimental models but it failed to show effect through two phase III clinical trials in patients with traumatic brain injury.

Keywords: neurogenesis, steroid hormones, cognition, stress, epileptogenesis.

\section{Sažetak}

Potreban je bio skoro čitav vek da bi dogma o nemogućnosti proliferacije i regeneracije unutar centralnog nervnog sistema (CNS) odraslih jedinki bila prevaziđena. Zahvaljujući velikom broju istraživanja u poslednje tri decenije, fenomen neurogeneze kod čoveka postao je nepobitna činjenica. Ideje o mogućim terapijskim implikacijama neuralnih stem ćelija u lečenju moždanog udara, traumatskog oštećenja mozga i kičmene moždine kao i neurodegenerativnih oboljenja osnova su velikih istraživačkih projekata

Nakon završetka razvoja CNS-a, neurogeneza se u odraslih jedinki kontinuirano nastavlja u dva regiona mozga: subventrikularnoj zoni lateralnih komora i subgranularnoj zoni dentatnog girusa hipokamusa. Proces neurogeneze nameće bazična pitanja o regulatornim mehanizmima koji je podstiču ili suprimiraju, kao i pitanja o funkcionalnom značaju kod čoveka. Razvoj mozga od embrionalnog stadijuma do odraslog doba je pod uticajem steroidnih hormona (efekte ostvaruju genskom interakcijom ili neuromodulatornom ulogom preko jonskih kanala) te je izvestan efekat i u ponašanju jedinke. Studije ukazuju da gonadalni hormoni značajno utiču na procese učenja i pamćenja, ali bi relativna uloga ovih hormona ponaosob morala da bude protumačena u širem kontekstu vremena administracije, preekspozicionom treningu kao i tipu testa. Uticaj stresa je prepoznat takođe kao značajan činilac adultne neurogeneze, a najnovija funkcionalna ispitivanja ukazuju i na značaj suprotne rakcije, tj. uticaja mladih neurona na aktivnost hipotalamo-hipofizno-gonadne osovine i odgovora na stres.

Neurosteroidi (alopregnenolon, dihidroepiandrosteron) se sintetišu u samom moždanom tkivu gde su nadjeni u većim koncentracijama nego u krvi sisara. Brojni steroidogeni enzimi (važni u konverziji holesterola do neurosteroida) su targetovani u mozgu, kičmenoj moždini i delovima perifernog nervnog sistema. Značajan efekat neurosteroida pokazan je u procesima epileptogeneze.

Brojne studije pokušavaju da odgovore na pitanje u kojoj meri je neurogeneza i preživljavanje neurona u funkciji kognicije uslovljena i uticajem hormona. Eksperimentalno potvrđene regenerativne sposobnosti progesterona su upotrebljene kroz III fazu kliničkih ispitivanja kod pacijenata sa traumatskim oštećenjem mozga.

Ključne reči: neurogeneza, steroidni hormoni, kognicija, stres, epileptogeneza

\section{NEUROGENEZA: ISTORIJSKE PERSPEKTIVE I OPŠTA RAZMATRANJA}

Početkom dvadesetog veka Cajal S.R., je zapiso: „U zrelim centrima, nervni putevi su nešto zaustavljeno, završeno i nepromenljivo. Sve može da umre, nista se ne regeneriše“ (1).
Sa početka 21. veka doktrina je promenjena, zapravo neurogeneza je definisana kao proces stvaranja novih nervnih ćelija u mozgu odrasle jedinke iz neuralnih stem ćelija (NSĆ) (2).

Sve do kraja XX veka centralna pretpostavka neuronauke ogledala se u vidjenju čuvenog naučnika Santiago 
Ramon y Cajala $(1,3,4)$, da se stvaranje novih nervnih ćelija završava u ranom postnatalnom periodu. Uprkos tome što je Allen E., već 1912. god (5), dala nagoveštaj dokaza o postojanju adultne neurogeneze uočivši mitotička vretena u ćelijama zida lateralnih komora kod Wistar albino pacova starih 120 dana, nalazi su ostali neprimetni za neuronaučno društvo. Tek 60 . godina ideja o postojanju neurogeneze potkrepljena je novootkrivenim naučnim činjenicama. Koristeći radioaktivni 3H-timidin, nukleozid koji ćelije preuzimaju u $\mathrm{S}$ fazi pripreme za mitozu, Alltman J. $(6,7)$ autoradiografski identifikuje proliferišuće neurone $\mathrm{u}$ dentatnom girusu himpokampusa kod odraslih pacova. Alltman prvi ukazuje i na postojanje neuralnih stem ćelija u subventrikularnoj zoni lateralnih komora (SVZ) (7) i detaljno opisuje njihovu migraciju do olfaktivnog bulbusa $(\mathrm{OB})$ gde sazrevaju u neurone (8).Validnost ovih rezultata osporena je nedostatkom dokaza da se zaista radi o proliferišućim neuronima. Kaplan M. je potkrepio Alltmanove rezultate tehnikom elektronske mikroskopije, čime je morfološki potvrdio neuronsku prirodu autoradiografski obeleženih ćelija petnaest godina kasnije (9-11).

Uprkos objavljivanju rezultata u najprestižnijim časopisima, zbog ograničenih tehničkih uslova tadašnjeg doba, nepostojanja imunohistohemijskih metoda i time funkcionalne identifikacije ćelija, neurogeneza je trpela kontinuirani skepticizam (12). U prilog tome, vodeći naučnik u oblasti neurorazvoja, Rakić P., (1985. g) objavio je rezultate istraživanja na Resus majmunima dobijene takodje autoradiografskim beleženjem timidinom. Rakić nije identifikovao niti jednu obeleženu ćeliju sa morfološkim osobinama neurona $\mathrm{u}$ ispitivanim strukturama mozga (13). Iz tih razloga, izneo je zaključke da su kod odraslih primata stabilne neuronske populacije biološki neophodne za organizam čije preživljavanje počiva na naučenom ponašanju, sticanom tokom dugog vremena. Navedeno je tada, takođe, da socijalno i kognitivno ponašanje primata zahteva odsustvo neurogeneze (14-16). Razvoj tehnike omogućio je da istorija rada čuvenog skeptika neurogeneze, Rakića P., nedugo potom bude ispisana potvrdnim dokazima o postojanju adultne neurogeneze $\mathrm{u}$ dentatnom girusu primata (17).

Sa druge strane, '80tih godina Nottebom F. i saradnici započeli su istraživanja neuronske osnove učenja pesama kod ptica i otkrili izrazitu promenljivost veličine dva jedra koja su bila definisana kao krucijelna u ovom procesu (18). Obeležavanjem radioaktivnim timidinom uočeno je postojanje neurogeneze u njima kao i zavisnost te pojave od pola jedinke i godišnjeg doba u kom je istraživanje rađeno (19). Došlo se do zaključka da je testosteron preko moždanog neurotrofičkog faktora (engl. brain derived neurotrofic factor, BDNF) bio upravo odgovoran kako za stvaranje novih neurona, tako i za njihovo preživljavanje i funkcionalnu integraciju (20-22).
NeURALNE STEM ĆELIJE: POREKLO, REGULACIJA AKTIVNOSTI

Adultne neuralne stem ćelije definisane su njihovom sposobnošću za samoobnavljanjem i diferencijacijom u neurone, astrocite i oligodendrocite $(2,23)$. Naše razumevanje biologije adultnih neuralnih stem ćelja i neurogeneze nastalo je u najvećoj meri zahvaljujći istraživanjima na glodarima (24). Neurogeneza je nedvosmisleno potvrđena u dva regiona mozga: subventrikularnoj zoni lateralnih komora (SVZ) i subgranularnoj zoni (SGZ) dentatnog girusa hipokampusa $(25,26)$. Neuralne stem ćelje u SVZ i SGZ, iako dele mnoge sličnosti, predstavljaju dve populacije ćelija koje se značajno razlikuju kako u njihovom razvoju i organizaciji tako i u funkciji. U oba slučaja, NSĆ su astrocitima-slične ćelije kako morfološki, tako i eksprimacijom astrocitnog molekularnog markera-glijalni fibrilarni kiseli protein (engl. glial fibrillary acidic protein, GFAP) (27-30).

U subventrikularnoj zoni lateralnih komora, NSĆ se nazivaju B tipom ćelija, koje nakon aktivacije vrše upregulaciju receptora za epidermalni faktor rasta i progenitorski marker nestin, a potom se dele dajući tranzitorni tip ćelija C, koje se potom diferenciraju u tip A neuroblaste. Neuroblasti, identifikovani beleženjem doublecortinom, napuštaju SVZ i ekstenzivnom migracijom putem rostralne migratorne trake dolaze do OB gde sazrevaju u GABAergičke interneurone (31-34). Postojanje sličnog migratornog puta u mozgu odraslog čoveka vrlo je kontraverzna tema. Jasno je pokazano postojanje migracije neuroblasta iz zidova lateralnih komora u olfaktivnom traktu humanog fetalnog mozga, ipak pretpostavka je da ista sa razvojem prestaje (35). S obzirom da je SVZ najveći germinativni centar u mozgu odraslih sisara (36), postavljaju se fundamentalna pitanja: koja je funkcija neurogeneze u SVZ kod čoveka i da li istaživačke mogućnosti današnjice mogu da dopru do adekvatne spoznaje.

Sa druge strane, zahvaljujući specifičnoj morfologiji i jedinstvenom setu molekularnih markera, u SGZ su identifikovana dva tipa neuralnih progenitora. Ćelije tipa 1 eksprimiraju markere karakteristične za astrocite: nestin, GFAP, Sox2 (37-39) i dr. Ipak, morfološki i funkcionalno su vrlo različite od zrelih astrocita. Hipokampalni progenitor tip 2 ne eksprimira GFAP, a studije su pokazale da Sox2-pozitivne ćelije mogu da daju neurone i astrocite, što je predstavljao prvi in vivo dokaz stem ćelijskih osobina kod hipokampalnih progenitora (40). Istraživanja su pokazala da se u hipokampusu čoveka neurogeneza održava tokom čitavog života što je slučaj i u životinja (41-43).

Iako su tipovi neuralnih progenitora jasno definisani, do danas se ne zna sa sigurnošću koji faktori i u kojoj meri regulišu adultnu neurogenezu. Pretpostavke su da diferencijaciju u astrocite ili neuroblaste određuju 
upravo ekstracelularni faktori neurogene niše u kojoj se NSĆ nalaze $(44,45)$. Kao odgovor na funkcionalne zahteve tj neuronsku stimulaciju, u ćelijama u diferencijaciji dolazi do aktiviranja seta ranih gena koji kodiraju transkripcione faktore koji pak regulišu ekspresiju gena uključenih $\mathrm{u}$ određivanje fenotipa budućih neurona (46). Pokazano je kasnije, da su upravo ovi geni odgovorni u procesima neuronske plastičnosti i konsolidacije pamćenja $(47,48)$. U in vitro uslovima je pokazano da oštećenje moždanog tkiva indukuje proliferaciju kortikalnih astrocita u neurone (49) dok u in vivo uslovima, nije poznato da astrociti osim procesa samoobnavljanja mogu da generišu drugu vrstu ćelija (neurone). Usled pomenutog procesa dolazi do stvaranja glijalnog ožiljka. Sa druge strane, identifikovano je da u odgovoru na moždani udar, ćelije prednjeg dela SVZ koje su inače u stanju mirovanja, generišu kako astrocite tako i neuroblaste koji potom migriraju na mesto insulta (50).

Neurogeneza kao proces, može biti poboljšana uticajem na proliferaciju progenitora, diferencijaciju i preživnjavanje diferentovanih ćelija. Mnogi faktori su prepoznati kao činioci u ovim procesima, a u velikoj meri se ispituje uticaj steroidnih hormona (51).

HIPOKAMPUS I KOGNITIVNE FUNKCIJE:ODNOS PREMA NEUROGENEZI I GONADALNIM HORMONMA

Efikasnost adultne neurogeneze podrazumeva dve komponente: broj novostvorenih ćelija, kao i broj preživelih ćelija u određenoj tački vremena. Nivo hipokampalne neuronske proliferacije je veći kod ženki (52), dok je preživljavanje ćelija veće kod jedinki muških glodara $(53,54)$. Zavaljujući razlikama u hormonskom statusu među polovima, jasno proizilazi njihov uticaj na adultnu neurogenezu (55). Brojne studije su pokazale da estradiol utiče na povećanje ćelijske proliferacije u SGZ, ali i na smanjenje preživljavanja novostvorenih neurona kod ženki glodara, te da ovi efekti zavise od doze i vremena administracije (56-58). Uticaj testosterona na proliferaciju neurona u SGZ kao i u SVZ takođe se pokazao pozitivnim, međutim pretpostavlja se da se ovi efekti ostvaruju preko estrogenskih receptora, zahvaljujući metaboličkoj konverziji testosterona u estrogen (59). Nasuprot tome, testosteron i njegov metabolit, dihidrotestosteron, deluju pozitivno na proliferaciju i preživljavanje ćelija aktiviranjem i androgenih receptora. Ovo se ne odnosi na dentatni girus, koji najverovatnije odgovara na stimulaciju estrogenskih receptora $\operatorname{Era~i~} \operatorname{Er} \beta$ $(60,61)$. Umerena fizička aktivnost koja ima za posledicu sintezu dihidrotesterona stimuliše neurogenezu u adultnom hipokampusu (62). Pretpostavlja se da se ovi efekti ostvaruju preko NMDA glutamatskih receptora te aktivacijom sinteze BDNF i VEGF (engl. vascular endotelial growth factor) (63).
Funkcionalna integracija mladih neurona u postojeće neuronske krugove - adultna neurogeneza u hipokampusu i kognicija, danas su predmet sve većeg broja istraživanja $(64,65)$. Eksperimentalni radovi ukazuju da smanjen nivo neurogeneze redukuje sposobnost učenja i prostornog pamćenja (dugotrajno i kratkotrajno) (66, 67). Nasuprot jasnom odnosu neurogeneze i hipokampus-zavisnih oblika učenja i pamćenja, pokazano je da veći broj neurona nije siguran parametar boljeg ishoda u rešavanju kognitivnih testova (68). Uticaj gonadalnih hormona na procese neurogeneze i hipokampus-zavisne funkcije, uočen je u eksperimentima na ženkama glodara sa intaktnim estrusnim ciklusom $(69,70)$. Ženke pacova u proestrusu (visok estradiol i progesteron) imaju lošiji rezultat u testovima prostornog učenja (ispitivan na Morisovom vodenom lavirintu) u poređenju sa ženkama u estrusu (nizak estradiol) (71-73). Uloga stresa tokom proestrusa je verovatan razlog umanjenom značaju estrusnog ciklusa na performanse prostornog pamćenja (74).

S ozirom da kod ženki pacova i estrogen i progesteron fluktuiraju tokom estrusnog ciklusa, brojne studije su pokušale da nađu relativni doprinos svakog od ovih hormona na učenje i pamćenje. Chesler i Juraska (75) su našli da kod ovariektomisanih životinja administracija estradiola ili progesterona $4 \mathrm{~h}$ pre testiranja u Morisovom vodenom lavirintu ne rezultira značajnim efektima, dok oba hormona administrirana zajedno utiču na lošiji ishod pamćenja. Za razliku od prethodnih studija, akutna administracija estradiola i progesterona odmah nakon treninga značajno poboljšava pamćenje pozicije objekta (74).

Brojnim testovim je pokazano da je ovariektomija asocirana sa lošijim kognitivnim funkcijama kod žena i ženki glodara (76-78) dok tretman estradiolom može da povrati smanjen nivo kognitivnih funkcija uzrokovanih ovariektomijom (80). Nauka ne bi bila interesantna da ne postoje oprečni rezultati: ovariektomija oštećuje prostornu kogniciju kod adultnih, dok je poboljšava kod starijih žena (81).

Adultna neurogeneza i veličina hipokampusa značajno su smanjeni u trudnoći (82) i kao posledica nastaje pad radne memorije i prostornog snalaženja u odnosu na negravidne žene (83). Oprečni zaključci isto dizajniranih studija ukazuju da rezultati testova zavise od pola fetusa (84). Zapravo, majke koje nose muški fetus imaju bolje rezultate na testovima (radne memorije i mentalne rotacije) i oni perzistiraju do 19 meseci nakon porođaja.

S obzirom na široku rasprostranjenost progesteronskih receptora na svim vrstama ćelija u nervnom sistemu, opravdan je njegov uticaj na ponašanje, emocije, zapaljenske reakcije, funkciju mitohondrija, neurogenezu i regeneraciju, mijelinizaciju i oporavak u modelima traumatskog oštećenja mozga (85). Verovanja u terapijske 
mogućnosti progesterona sežu čak do III faze kliničkih studija traumatskog oštećenja mozga, gde se na žalost nije pokazao značajnim u odnosu na placebo $(86,87)$. Ipak, istraživanja sa ciljem boljeg dizajna studija i analize rezultata se nastavljaju.

\section{NeUROgENEZA I STRES}

Hipokampus predstavlja strukturnu osnovu učenja, kontrolor i efektor je našeg pamćenja i prostorne navigacije dok, stres oblikuje emocije i ponašanje. Hipokampus učestvuje u kontroli stresa i raspoloženja, za koju je najverovatnije odgovorna neurogeneza (88). Sve navedeno je razlog što se uzrok određenim psihijatrijskim oboljenjima može naći u poremećenoj neurogenezi u hipokampusu (89). Jasno je definisan model depresije kod životinja izazvan blagim hroničnim stresom, čije se posledice na ćelijskom nivou ogledaju u smanjenoj neurogenezi (90). U eksperimentima gde je adultna neurogeneza bila smanjena bez primene stresa, životinje nisu pokazivale depresiji-slično ponašanje, čime je sugerisano da neurogeneza može imati modulatornu ulogu u odogovoru na stres (91). Nedavne studije ukazuju da zreli neuroni smanjuju neuroendokrini odgovor na stres tj. da vrše ulogu "amortizera stresa" (92).

Smanjena neurogeneza (transgena modifikacija ili izlaganje radijaciji), povećava nivo hormona koji čine odgovor na stres što potvrđuje smanjenje supresije glukokortikoida egzogenim deksametazonom kod neurogeneza-deficijentnih miševa (93). Adultna neurogeneza pojačava glukokokortikoidima posredovanu negativnu povratnu spregu u hipotalamo-hipofizno-gonadnoj osovini

Uticaj stresa na rezultate $\mathrm{u}$ bihejvioralnim testovima $\mathrm{u}$ mnogome zavisi od nivoa endogenih hormona koji je uslovljen periodom ciklusa u kom se ispitivana životinja nalazi. Reaktivnost na stres bila je mnogo veća kod ženki pacova u proestrusu u odnosu na jedinke u estrusu (94).

Uočeno je da akutni stress (izazvan nepoznatom sredinom i plivanjem u Morisovom vodenom lavirintu) negativno utiče na prostorno snalaženje ženki (95), dok stres izazvan imobilizacijom pozitivno utiče na prostorno pamćenje u Y lavirintu kako kod ženki u proestrusu tako i kod onih u estrusu (96). Neaverzivne aktivnosti kao što su fizička aktivnost, seksualno iskustvo i dr. koje uzrokuju akutno lučenje hormona stresa, takodje pozitivno utiču na adultnu neurogenezu $(97,98)$.

Jasno je da ne postoji jednostavan, linearan odnos između hormona stresa i adultne neurogenze. Adultna neurogeneza teoretski utiče na smanjenje stresnog odgovora i suštinski uspostavlja adekvatan dinamizam istog. Moglo bi se zaključiti, da disfunkcija ovih mehanizama doprinosi riziku nastanka depresije $(99,100)$.

\section{NEUROGENEZA, HORMONI I EPILEPTOGENEZA}

Epilepsije pokazuju značajne razlike $\mathrm{u}$ incidenci, progresiji, težini napada i odgovoru na terapiju među polovima. Efekti uticaja gonadalnih hormona tokom moždanog razvoja oslikavaju se permanentnim strukturnim razlikama među polovima (101). Ipak, precizni mehanizmi uticaja na razvoj moždanih struktura i neuronskih krugova odgovornih za razlike u kontroli moždane ekscitabilonosti i dalje su nejasni (102). Ciklične promene nivoa estrogena i progesterona veoma su važne u patogenezi katamenijalne epilepsije, oblika bolesti kod žena gde je prevalenca konvulzivnih napada zavisna od menstrualnog ciklusa (103). U najvećem broju istraživanja, uočeni su prokonvulzivni efekti estrogena, dok je administracija progesteron imala snažnu antiepileptičnu aktivnost (104). Nedavnom multicentričnom kliničkom studijom ispitani su terapijski efekti progesterona kod žena sa epilepsijom, a rezultati su pokazali značajno bolji odgovor kod žena sa perimenstrualnom egzacerbacijom simptoma u odnosu na kontole (105). Progesteron predstavlja jedan od intermedijernih prekursora $\mathrm{u}$ sintezi neurosteroida (106). Neurosteroidi (alopregnanolon, androstenedione, alotetrahidrodeoksikortikosteron -THDOC) pozitivnom alosteronom modulacijoim GABA-A receptora smanjuju ćelijsku ekscitabilnost (107). U našoj labaroatoriji su razvijeni metafitom indukovan, homocisteinski i lindanski modeli epilepsije, te ispitani brojni antikonvulzivni i prokonvulzivni faktori (108-113). Administracija alopregnanolola u homocisteinskom modelu epilepsije kod pacova nije dala očekivane antikonvulzivne efekte (neobjaveljeni rezultati). Ispitivanja na ovom polju tek predstoje. S druge strane, pokazano je da administracija finasterida u modelu hepatične encefalopatije doprinosu povećanju ekspresije markera neurona i glije, kao i poboljšanju motornih i EEG fenomena. Istraživanja uticaja testosteron undekanoata na kogniciju (neurogenezu), epilepsiju, fizičku aktivnost, anksioznost, nocicepciju i metabolizam adultnih ženki pacova je u toku.

\section{ZaKLJUČAK}

Uticaj steroidnih hormona na procese adultne neurogeneze je neizostavan. Kvantifikacija adultne neurogeneze u hipokampusu je pokazala da je oko trećina neurona sposobna za procese samoobnavljanja te da može da se izrazi sa $1,75 \%$ od ukupne neuronske populacije hipokampusa tokom jedne godine, i ovaj broj sa starenjem opada. Translacioni aspekti naših studija mogli bi imati značaj s obzirom na sve veću incidencu degenerativnih i psihijatrijskih oboljenja, moždanih udara kao i traumatskih povreda mozga i perifernih nerava. 


\section{NAPOMENA}

\section{Rad je usmeno izložen na mini simpozijumu Translaci-} oni aspekti eksperimentalnih modela u neurofiziologiji i neuroendokrinologiji na 44. simpozijumu Stremljenja i novine u medicini, Medicinski fakultet u Beogradu, 07.12.2015. godine.

\section{Literatura}

1. Ramon y Cajal, S. Degeneration and regeneration of the nervous system. Haffner Publishing Co. New York, 1928; 2: 750.

2. Gage, F.H. Mammalian neural stem cells. Science 2000; 287: 14331438.

3. Rakic, P. DNA synthesis and cell division in the adult primate brain. Ann. NY Acad. Sci, 1985; 457: 193-211.

4. Jacobson, M. Developmental Neurobiology. Holt, Rinehart, and Winston, New York, 1970.

5. Allen E. The cessation of mitosis in the central nervous system of albino rats. 1912, The Journal of Comparative Neurology; 22: 548-567.

6. Altman J. Autoradiographic investigation of cell proliferation in the brains of rats and cats. Anat Rec. 1963; 145: 573-91.

7. Altman J, Das GD. Autoradiographic and histological evidence of postnatal hippocampal neurogenesis in rats. J Comp Neurol. 1965; 124(3) 319-35.

8. Altman J. Autoradiographic and histological studies of postnatal neurogenesis. IV. Cell proliferation and migration in the anterior forebrain, with special reference to persisting neurogenesis in the olfactory bulb. J Comp Neurol. 1969; 137(4): 433-57.

9. Kaplan MS, Hinds JW. Neurogenesis in the adult rat: electron microscopic analysis of light radioautographs. Science. 1977; 197 (4308) 1092-4.

10. Kaplan MS, Bell DH. Mitotic neuroblasts in the 9-day-old and 11-month-old rodent hippocampus. J Neurosci. 1984; 4(6): 1429-41.

11. Kaplan MS, McNelly NA, Hinds JW. Population dynamics of adultformed granule neurons of the rat olfactory bulb. J Comp Neurol. 1985 239 (1): $117-25$

12. Weiss, P. A. in The Neurosciences, Second Study Program (ed. Schmitt, F. O.) 53-61 (Rockefeller Univ. Press, New York, 1970)

13. Rakic P. Limits of neurogenesis in primates. Science. 1985; 227(4690) 1054-6.

14. Rakic, P. DNA synthesis and cell division in the adult primate brain. Ann. NY Acad. Sci 1985; 457: 193-211.

15. Eckenhoff, M. F, Rakic, P. Nature and fate of proliferative cells in the hippocampal dentate gyrus during the life span of the rhesus monkey. J. Neurosci. 1988; 8, 2729-2747.

16. Gross, C. G. in Tales in the History of Neuroscience. 137-178 (MIT Press, Cambridge, Massachusetts, 1998)

17. Kornack, D. R. \& Rakic, P. Continuation of neurogenesis in the hippocampus of the adult macaque monkey. Proc. Natl Acad. Sci. USA, 1999 $96,5768-5773$

18. Goldman SA, Nottebohm F. Neuronal production, migration, and differentiation in a vocal control nucleus of the adult female canary brain. Proc Natl Acad Sci U S A. 1983; 80 (8): 2390-4.

19. Nottebohm, F. Birdsong as a Model in Which to Study Brain Processes Related to Learning. The Condor, 1984; 86 (3), 227-236.

20. Rasika S, Nottebohm F, Alvarez-Buylla A. Testosterone increases the recruitment and/or survival of new high vocal center neurons in adult female canaries. Proc Natl Acad Sci U S A. 1994; 91 (17): 7854-7858.

21. Rasika S, Alvarez- Buylla A, Nottebohm F. BDNF mediates the effect of testosterone on the survival of new neurons in an adult brain. Neuron, 199; 22: 53-62.

22. Li XC, Jarvis ED, Alvarez-Borda B, Lim DA, Nottebohm F. A relation between behavior, neurotrophin expression and new neuron survival. Proc Natl Acad Sci USA, 2000; 97: 8584-8589.

23. Temple S. The development of neural stem cells. Nature. 2001; 414 (6859): 112-7.

24. Ochi T, Nakatomi H, Ito A, Imai H, Okabe S, Saito N. Temporal changes in the response of SVZ neural stem cells to intraventricular administration of growth factors. Brain Res. 2016: S0006-8993(16)30023-3. [Epub ahead of print]
25. Jessberger S, Clark R, Broadbent J, Clemenson G, Consiglio A. et al Dentate gyrus-specific knockdown of adult neurogenesis impairs spatial and object recognition memory in adult rats Learn Mem. 2009; 16 (2): 147-154.

26. Kempermann G, Kuhn G, Gage F. More hippocampal neurons in adult mice living in an enriched environment. Nature, 1997; 386: 493-495.

27. Alvarez-Buylla A, García-Verdugo JM, Tramontin AD. A unified hypothesis on the lineage of neural stem cells. Nat Rev Neurosci. 200; 2 (4): $287-93$

28. Doetsch F, Alvarez-Buylla A. Network of tangential pathways for neuronal migration in adult mammalian brain. Proc Natl Acad Sci USA. 1996; 93 (25): 14895-900

29. Doetsch F, Caillé I, Lim A, García-Verdugo JM, Alvarez-Buylla A. Subventricular Zone Astrocytes Are Neural Stem Cells in the Adult Mammalian Brain. Cell, 1999; 97 (6): 703-716.

30. Ming GL, Song H. Adult neurogenesis in the mammalian brain: significant answers and significant questions. Neuron. 2011; 70 (4): 687-702.

31. Carleton A, Petreanu LT, Lansford R, Alvarez-Buylla A, Lledo PM. Becoming a new neuron in the adult olfactory bulb. Nat. Neurosci. 2003; 6: 507-518.

32. Whitman MC, Greer CA. Adult neurogenesis and the olfactory system. Prog Neurobiol. 2009; 89 (2): 162-75.

33. C Lois, A Alvarez-Buylla. Long-distance neuronal migration in the adult mammalian brain. Science 1994: 264 (5162): 1145-1148.

34. Nottebohm F. Why Are Some Neurons Replaced in Adult Brain? J Neurosci, 2002; 22 (3): 624-628;

35. Curtis M, Kam M, Nannmark U, Anderson MF, Zetterstrom Axell M, et al. Human Neuroblasts Migrate to the Olfactory Bulb via a Lateral Ventricular Extension. Science, 2007; 315 (5816): 1243-1249.

36. Wang C, Liu F, Liu YY, Zhao CH, You Y, Wang L, Zhang J, Wei B, Ma T, Zhang Q, Zhang Y, Chen R, Song H, Yang Z. Identification and characterization of neuroblasts in the subventricular zone and rostral migratory stream of the adult human brain. Cell Res. 2011; 21 (11): 1534-50.

37. Fukuda S, Kato F, Tozuka Y, Yamaguchi M, Miyamoto Y, Hisatsune T. Two distinct subpopulations of nestin-positive cells in adult mouse dentate gyrus. J Neurosci. 2003; 23 (28): 9357-66.

38. Suh H, Deng W, Gage FH. Signaling in adult neurogenesis. Annu Rev Cell Dev Biol 2009; 25: 253-275.

39. Suh H, Consiglio A, Ray J, Sawai T, D’Amour KA, Gage FH. In vivo fate analysis reveals the multipotent and self-renewal capacities of Sox2+ neural stem cells in the adult hippocampus. Cell Stem Cell. 2007; 1(5): 515-28.

40. Eriksson PS, Perfilieva E, Björk-Eriksson T, Alborn AM, Nordborg C et al. Neurogenesis in the adult human hippocampus. Nat Med. 1998; 4 (11): 1313-7.

41. Knoth R, Singec I, Ditter M, Pantazis G, Capetian P et al. Murine features of neurogenesis in the human hippocampus across the lifespan from 0 to 100 years. PLoS One. 2010; 5 (1): e8809.

42. Spalding KL, Bergmann O, Alkass K, Bernard S, Salehpour M et al. Dynamics of hippocampal neurogenesis in adult humans. Cell. 2013; 153 (6): 1219-27.

43. Barnabé-Heider F, Göritz C, Sabelström H, Takebayashi H, Pfrieger FW, et al. Origin of new glial cells in intact and injured adult spinal cord. Cell Stem Cell. 2010; 7 (4): 470-82.

44. Buffo A, Rite I, Tripathi P, Lepier A, Colak D, et al. Origin and progeny of reactive gliosis: A source of multipotent cells in the injured brain. Proc Natl Acad Sci U S A. 2008; 105 (9): 3581-6.

45. Carlén M, Meletis K, Göritz C, Darsalia V, Evergren E, et al. Forebrain ependymal cells are Notch-dependent and generate neuroblasts and astrocytes after stroke. Nat Neurosci. 2009; 12 (3): 259-67.

46. Sheng M, Greenberg ME. The regulation and function of $\mathrm{c}$-fos and other immediate early genes in the nervous system. Neuron. 1990; 4 (4): 477-85. 
47. Mokin M, Keifer J. Expression of the immediate-early gene-encoded protein Egr-1 (zif268) during in vitro classical conditioning. Learn Mem. 2005; 12 (2): 144-149.

48. Jones MW, Errington ML, French PJ, Fine A, Bliss TVP. et al. A requirement for the immediate early gene Zif 268 in the expression of late LTP and long-term memories. Nat. Neurosci, 2001; 4: 289-296.

49. Fowler CD, Freeman ME, Wang Z. Newly proliferated cells in the adult male amygdala are affected by gonadal steroid hormones. J. Neurobiol, 2003; 57: 257-269.

50. Falconer EM, Galea LAM. Sex differences in cell proliferation, cell death and defensive behavior following acute predator odor stress in adult rats. Brain Res, 2003; 975: 22-36.

51. Van Praag H, et al. Functional neurogenesis in the adult hippocampus. Nature, 2002; 415: 1030-1034.

52. Galea LA, McEwen BS. Sex and seasonal differences in the rate of cell proliferation in the dentate gyrus of adult wild meadow voles. Neuroscience. 1999; 89 (3): 955-64.

53. Westenbroek C, Den Boer JA, Veenhuis M, Ter Horst GJ. Chronic stress and social housing differentially affect neurogenesis in male and female rats. Brain Res Bull. 2004; 64 (4): 303-8.

54. Dalla C, Papachristos EB, Whetstone AS, Shors TJ. Female rats learn trace memories better than male rats and consequently retain a greater proportion of new neurons in their hippocampi. Proc Natl Acad Sci U S A. 2009; 106 (8): 2927-32.

55. Galea LA, Spritzer MD, Barker JM, Pawluski JL.Gonadal hormone modulation of hippocampal neurogenesis in the adult. Hippocampus. 2006; 16 (3): 225-32.

56. Ormerod BK, Falconer EM, Galea LA. N-methyl-D-aspartate receptor activity and estradiol: separate regulation of cell proliferation in the dentate gyrus of adult female meadow vole. J Endocrinol. 2003; 179 (2): 155-63.

57. Barker JM, Galea LA. Repeated estradiol administration alters different aspects of neurogenesis and cell death in the hippocampus of female, but not male rats. Neuroscience. 2008; 152(4): 888-902.

58. Barha CK, Lieblich SE, Galea LA. Different forms of oestrogen rapidly upregulate cell proliferation in the dentate gyrus of adult female rats. J Neuroendocrinol. 2009; 21 (3): 155-66.

59. Farinetti A, Tomasi S, Foglio B, Ferraris A, Ponti G, et al.Testosterone and estradiol differentially affect cell proliferation in the subventricular zone of young adult gonadectomized male and female rats. Neuroscience. 2015; 286: 162-70.

60. Hamson DK, Wainwright SR, Taylor JR, Jones BA, Watson NV, Galea LA. Androgens increase survival of adult-born neurons in the dentate gyrus by an androgen receptor-dependent mechanism in male rats. Endocrinology. 2013; 154 (9): 3294-304

61. Mazzucco CA, Lieblich SE, Bingham BI, Williamson MA, Viau V, Galea LA. Both estrogen receptor alpha and estrogen receptor beta agonists enhance cell proliferation in the dentate gyrus of adult female rats. Neuroscience. 2006; 141 (4): 1793-800.

62. M, Hojo Y, Inoue K, Matsui T, Kawato S. et al. Mild exercise increases dihydrotestosterone in hippocampus providing evidence for androgenic mediation of neurogenesis. Proc Natl Acad Sci U S A. 2012; 109 (32): 13100-13105.

63. Louissaint A Jr, Rao S, Leventhal C, Goldman SA. Coordinated interaction of neurogenesis and angiogenesis in the adult songbird brain. Neuron. 2002; 34 (6): 945-60.

64. Jessberger S, Kempermann G. Adult-born hippocampal neurons mature into activity-dependent responsiveness. Eur J Neurosci. 2003; 18 (10): $2707-12$

65. Shors TJ, et al. Neurogenesis in the adult is involved in the formation of trace memories. Nature, 2001; 410: 372-376.

66. Saxe MD, Battaglia F, Wang JW, Malleret G, David DJ, et al. Ablation of hippocampal neurogenesis impairs contextual fear conditioning and synaptic plasticity in the dentate gyrus, Proc. Natl. Acad. Sci. USA, 2006; 103: 17501-17506.

67. Lopes da Silva FH, Gorter JA, Wadman WJ. Kindling of the hippocampus induces spatial memory deficits in the rat. Neurosci. Lett. 1986; 63: $115-120$.

68. Jessberger S, Nakashima K, Clemenson GD Jr, Mejia E, Mathews E. et al. Epigenetic modulation of seizure-induced neurogenesis and cognitive decline, J. Neurosci. 2007; 27: 5967-5975.
69. Galea LA, Spritzer MD, Barker JM, Pawluski JL. Gonadal hormone modulation of hippocampal neurogenesis in the adult, Hippocampus, 2006; 16: 225-232.

70. Tanapat P, Hastings NB, Reeves AJ, Gould E. Estrogen stimulates a transient increase in the number of new neurons in the dentate gyrus of the adult female rat, J. Neurosci. 19 (1999) 5792-5801.

71. Warren SG, Juraska JM. Spatial and nonspatial learning across the rat estrous cycle. Behav. Neurosci, 1997; 111: 259-266.

72. Frye CA. Estrus-associated decrements in a water maze task are limited to acquisition. Physiol. Behav. 1995; 57: 5-14.

73. Galea L, Kavaliers M, Ossenkopp KP, Hampson E. Gonadal hormone levels and spatial learning performance in the Morris water maze in male and female meadow voles, Microtus pennsylvanicus. Horm. Behav, 1995; 29: 106-125.

74. Berry B, McMahan R, Gallagher M. Spatial learning and memory at defined points of the estrous cycle: effects on performance of a hippocampal-dependent task. Behav. Neurosci, 1997; 111: 267-274.

75. Chesler EJ, Juraska JM. Acute administration of estrogen and progesterone impairs the acquisition of the spatial morris water maze in ovariectomized rats. Horm. Behav, 2000; 38: 234-242.

76. Shors TJ, Townsend DA, Zhao M, Kozorovitskiy Y, Gould E. Neurogenesis may relate to some but not all types of hippocampal-dependent learning. Hippocampus, 2002; 12: 578-584.

77. Sherwin BB, Henry JF. Brain aging modulates the neuroprotective effects of estrogen on selective aspects of cognition in women: a critical review. Front. Neuroendocrinol. 2008; 29: 88-113.

78. Gibbs RB. Estrogen therapy and cognition: a review of the cholinergic hypothesis. Endocr. Rev, 2010; 31: 224-253.

79. Hogervorst E, Williams J, Budge M, Riedel W, Jolles J. The nature of the effect of female gonadal hormone replacement therapy on cognitive function in post-menopausal women: a meta-analysis. Neuroscience, 2000; 101: 485-512.

80. Bimonte-Nelson HA, Singleton RS, Hunter CL, Price KL, Moore AB, et al. Ovarian hormones and cognition in the aged female rat: I. Longterm, but not short-term, ovariectomy enhances spatial performance. Behav. Neurosci, 2003;117: 1395-1406.

81. Barha CK, Lieblich SE, Chow C, Galea LA. Multiparity-induced enhancement of hippocampal neurogenesis and spatial memory depends on ovarian hormone status in middle age. Neurobiol. Aging, 2015; 36: 2391-2405.

82. Rolls A, Schori H, London A, Schwartz M. Decrease in hippocampal neurogenesis during pregnancy: a link to immunity. Molecular Psychiatry, 2008; 13(5): 468-469.

83. Henry JF, Sherwin BB. Hormones and cognitive functioning during late pregnancy and postpartum: a longitudinal study. Behav Neurosci, 2012; 126 (1): 73-85.

84. Vanston CM, Watson NV. Selective and persistent effect of foetal sex on cognition in pregnant women. Neuroreport. 2005; 16 (7): 779-82.

85. Lucassen PJ, Heine VM, Muller MB, van der Beek EM, Wiegant VM, et al. Stress, depression and hippocampal apoptosis. CNS Neurol Disord Drug Targets. 2006; 5 (5): 531-46.

86. Wright DW, Yeatts SD, Silbergleit R, Palesch YY, Hertzberg VS, et al. Very early administration of progesterone for acute traumatic brain injury. N Engl J Med. 2014; 371 (26): 2457-66.

87. Skolnick BE, Maas AI, Narayan RK, van der Hoop RG, MacAllister T, et al. A clinical trial of progesterone for severe traumatic brain injury. N Engl J Med. 2014; 371 (26): 2467-76.

88. Wong EY, Herbert J. The corticoid environment: a determining factor for neural progenitors' survival in the adult hippocampus. Eur J Neurosci. 2004; 20 (10): 2491-8

89. Mirescu C, Gould E. Stress and adult neurogenesis. Hippocampus. 2006;16(3):233-8.

90. Petrik D, Lagace DC, Eisch AJ. The neurogenesis hypothesis of affective and anxiety disorders: are we mistaking the scaffolding for the building? Neuropharmacology. 2012; 62 (1): 21-34.

91. Snyder J, Soumier A, Brewer M, Pickel J, Cameron H. Adult hippocampal neurogenesis buffers stress responses and depressive behavior. Nature 2011; 476: 458-461

92. Surget A, Tanti A, Leonardo ED, Laugeray A, Rainer Q, et al. Antidepressants recruit new neurons to improve stress response regulation. Mol Psychiatry. 2011; 16 (12): 1177-88. 
93. Viau V, Meaney MJ. Variations in the hypothalamic-pituitary-adrenal response to stress during the estrous cycle in the rat. Endocrinology. 199; 129 (5): 2503-11.

94. Beiko J, Lander R, Hampson E, Boon F, Cain DP. Contribution of sex differences in the acute stress response to sex differences in water maze performance in the rat. Behav Brain Res. 2004; 151 (1-2): 239-53.

95. Conrad CD, Jackson JL, Wieczorek L, Baran SE, Harman JS, et al. Acute stress impairs spatial memory in male but not female rats: influence of estrous cycle. Pharmacol Biochem Behav. 2004; 78 (3): 569-79.

96. Leuner B, Glasper ER, Gould E. Sexual experience promotes adult neurogenesis in the hippocampus despite an initial elevation in stress hormones. PLoS One. 2010; 5 (7): e11597.

97. Kronenberg G, Bick-Sander A, Bunk E, Wolf C, Ehninger D, Kempermann G. Physical exercise prevents age-related decline in precursor cell activity in the mouse dentate gyrus. Neurobiol Aging.2006; 27 (10): 1505-13.

98. Christian KM, Song H, Ming GL. Functions and dysfunctions of adult hippocampal neurogenesis. Annu Rev Neurosci. 2014; 37: 243-62.

99. Temprana SG, Mongiat LA, Yang SM, Trinchero MF, Alvarez DD, et al. Delayed coupling to feedback inhibition during a critical period for the integration of adult-born granule cells. Neuron. 2015; 85 (1): 116-30.

100. Verrotti A, Latini G, Manco R, De Simone M, Chiarelli F. Influence of sex hormones on brain excitability and epilepsy. J Endocrinol Invest. 2007; 30 (9): 797-803.

101. Velíšková J. “Sex differences in seizure susceptibility,” in Encyclopedia of Basic Epilepsy Research ed. Schwartzkroin Philip., editor. (Oxford: Academic Press; ), 2009; 1-4.

102. Reddy DS. Neuroendocrine aspects of catamenial epilepsy. Horm Behav. 2013 ; 63 (2): 254-66.

103. Reddy DS. The role of neurosteroids in the pathophysiology and treatment of catamenial epilepsy. Epilepsy Res. 2009; 85 (1): 1-30.

104.Scharfman HE, MacLusky NJ. The influence of gonadal hormones on neuronal excitability, seizures, and epilepsy in the female. Epilepsia. 2006; 47(9): 1423-40.

105. Herzog AG, Fowler KM, Smithson SD, Kalayjian LA, Heck CN, et al. Progesterone vs placebo therapy for women with epilepsy: A randomized clinical trial. Neurology, 2012; 78 (24): 1959-66.Reddy DS. Role of anticonvulsant and antiepileptogenic neurosteroids in the pathophysiology and treatment of epilepsy. Front Endocrinol (Lausanne). 2011; 2. 38 .
106. Reddy D. S., Rogawski M. A. "Neurosteroids - endogenous regulators of seizure susceptibility and role in the treatment of epilepsy (Chapter 77)," in Jasper's Basic Mechanisms of the Epilepsies, 4th Edn eds Noebels J. L., Avoli M., Rogawski M. A., Olsen R. W., Delgado-Escueta A. V., editors. (New York, NY: Oxford University Press), 2012; 982-1000.

107. Hosie AM, Wilkins ME, Smart TG. Neurosteroid binding sites on GABA(A) receptors. Pharmacol Ther. 2007; 116 (1): 7-19.

108. Rasic-Markovic A, Rankov-Petrovic B, Hrncic D, Krstic D, Colovic M, Macut Dj, Djuric D, Stanojlovic O. The effect of subchronic supplementation with folic acid on homocysteine induced seizures. Acta Physiol Hung. 2015; 102 (2): 151-62.

109. Mladenović D, Hrncić D, Radosavljević T, Vucević D, Djurić D,et al. Dose-dependent anticonvulsive effect of ethanol on lindane-induced seizures in rats. Can J Physiol Pharmacol. 2008; 86 (4): 148-52.

110. Hrncić D, Vucević D, Rasić A, Radosavljević T, Mladenović D, et al. Moderate body hypothermia alleviates behavioral and EEG manifestations of audiogenic seizures in metaphit-treated rats. Can J Physiol Pharmacol. 2007; 85 (10): 1032-7.

111. Mladenović D, Petronijević N, Stojković T, Velimirović M, Jevtić G, et al. Finasteride Has Regionally Different Effects on Brain Oxidative Stress and Acetylcholinesterase Activity in Acute Thioacetamide-Induced Hepatic Encephalopathy in Rats. PLoS One. 2015; 10 (8):e0134434.

112. Mladenović D, Hrnčić D, Petronijević N, Jevtić G, Radosavljević T, et al. Finasteride improves motor, EEG, and cellular changes in rat brain in thioacetamide-induced hepatic encephalopathy. Am J Physiol Gastrointest Liver Physiol. 2014; 307 (9): G931-40.

113. Spalding K, Bergmann O, Alkass K, Bernard S,Salehpour M, et al. Dynamics of hippocampal neurogenesis in adult humans. Cell. 2013; 153 (6): 1219-1227. 